\title{
Earnings-consumption betas and stock valuation
}

\author{
Claude Bergeron* \\ École des sciences de l'administration (ESA), \\ Université du Québec (TÉLUQ), \\ Québec, Québec, Canada \\ Email: claude.bergeron@teluq.ca \\ *Corresponding author
}

\section{Jean-Pierre Gueyie and Komlan Sedzro}

École des sciences de la gestion (ESG), Université du Québec à Montréal (UQÀM), Montréal, Québec, Canada

Email: gueyie.jean-pierre@uqam.ca

Email: sedzro.k@uqam.ca

\begin{abstract}
This paper integrates the long-run covariance between aggregate consumption and firm earnings into the stock valuation process. After assuming that firms adjust their dividend payments toward a target dividend payout ratio, we use the intertemporal framework of the consumption capital asset pricing model (CCAPM) to explore the effect of systematic earnings risks on intrinsic stock values. Our main results show that the equilibrium price of a stock is positively related to its long-run earnings growth rate, and negatively related to its earnings-consumption beta, obtained from its long-run covariance between earnings growth and aggregate consumption growth. This suggests that long-run risk measured with earnings affects the theoretical value of a firm. Overall, our work suggests that the long-run concept of risk, using accounting earnings, represents an appropriate parameter for estimating the equity value of a firm.
\end{abstract}

Keywords: Stock valuation; Accounting beta; Intertemporal model; Long-run risk; CCAPM.

Reference to this paper should be made as follows: Bergeron, C., Gueyie, J-P. and Sedzro, K. (201X) 'Earnings-consumption betas and stock valuation', American J. Finance and Accounting, Vol. XX No. X, pp. XX-XX.

Biographical notes: Claude Bergeron, $\mathrm{PhD}$, is an Associate Professor of Finance at the University of Quebec (TÉLUQ), Canada. His research interests are in dividend policy, stock valuation, and intertemporal models. He has published research papers in international peer-reviewed journals such as Journal of Economics and Finance (Springer), Finance Research Letters (Elsevier), American Journal of Finance and Accounting (Inderscience), Finéco (Laval University), and International Journal of Economics and Finance (Toronto). Dr Bergeron is the corresponding author and can be contacted at: claude.bergeron@teluq.ca 
Jean-Pierre Gueyie, $\mathrm{PhD}$, is an Associate Professor at the School of Management, University of Quebec in Montreal. He received his Ph.D. from Laval University, Canada. He has published several papers in refereed scientific journals.

Komlan Sedzro, PhD, is a Professor at the School of Management of University of Quebec in Montreal (ESG-UQAM). Professor Sedzro has a broad range of research interests encompassing such areas as governance and performance evaluation of financial and microcredit institutions, corporate finance, optimal portfolio allocation, alternative investments including hedge funds, real estate and commodity derivatives, and the application of operational research methods in finance. He has published numerous articles and given presentations at various international conferences on these topics.

\section{Introduction}

According to Nekrasov and Shroff (2009), measurement of risk is perhaps the singlemost difficult task in valuing a security. In addition, according to the authors, if firm value is determined by fundamental variables such as earnings, then it would make sense to measure risk directly from fundamentals. These points of view are consistent with considerable research establishing the empirical or theoretical relation between accounting variables and market risk. For example, Beaver et al. (1970) find a significant correlation between standard market betas and accounting betas. ${ }^{1}$ Beaver and Manegold (1975) reveal a noteworthy association between market and accounting betas as measured under a variety of specifications. Ismail and Kim (1989) confirm prior findings about the significant relation between market betas and earnings betas, using four different accounting return variables. ${ }^{2}$ Karels and Sackley (1993) examine the statistical relationship between market and accounting betas in the U.S. banking industry. Their results indicate that the accounting betas are correlated with their market counterparts at levels similar to other (non-banking) studies. Baginski and Wahlen (2003) show that accounting betas are significantly positively related to the priced risk premiums in univariate regressions, but provide only limited explanatory power. Nekrasov and Shroff (2009) use the residual income valuation model to analytically derive a simple risk adjustment that equals the covariance between a firm's return on book equity (ROE) and economy-wide risk factors. Overall, their empirical results validate their fundamental accounting risk measures.

In a recent paper, $\mathrm{Da}$ (2009) proposes a novel way to estimate systematic risk, using, exclusively, long-run accounting earnings and aggregate consumption data. More precisely, the author proposes that the covariance between long-run accounting return and long-run aggregate consumption represents an appropriate empirical measure of risk. His results show that this measure of risk explains 58\% of the crosssectional variation in risk premia. If we add a duration measure, the model explains 
more than 80\%. Likewise, Da and Warachka (2009) construct an analyst earnings beta that measures the covariance between the cash flow innovation of an asset and those of the market. They find evidence that this cash flow risk measure is priced in the cross-section of expected stock returns (see also Schlueter and Sievers, 2014). As Goyal (2012, p. 29) mentioned in his asset pricing literature review, Da's model is very useful in explaining returns. Also, as Ball and Sadka (2015, p. 51) pointed out, studies on systematic earnings risk represent a promising avenue for further research.

In this paper, we construct a stock valuation model that integrates the long-run covariance between earnings and aggregate consumption.

Similarly to Da's study, our stock valuation model extends the important concept of long-run risk, first initiated by Bansal and Yaron (2004) and Bansal et al. (2005). Bansal and Yaron (2004) reveal that that consumption and dividend growth rates include a small long-run component that, in conjunction with Epstein and Zin's (1989) preferences, explains key asset market phenomena, and resolves the equity premium puzzle. Bansal et al. (2005) also show that cash flow betas, a measure of risk calculated by the long-run covariance between dividend growth and aggregate consumption growth, account for more than $60 \%$ of the cross-sectional variation in risk premia.

According to Beeler and Campbell (2012), the long-run risks model of Bansal and Yaron (2004) and Bansal et al. (2005), has attracted a great deal of attention, with important subsequent work by Hansen et al. (2008), Bansal et al. (2009), Bansal and Kiku (2011), and Bansal and Shaliastovich (2013), among others. Along these lines, Bergeron (2013-A) develops a theoretical stock valuation model that considers the long-run sensitivity of dividends to aggregate consumption, and Bergeron (2013-B) extends this model to various economic factors.

As Elton et al. (2014) noted, the correct way to determine the intrinsic value of stocks has occupied an enormous amount of effort over a long period of time. ${ }^{3}$ Indeed, following the traditional models of Gordon (1962), Basu (1977) and Ohlson (1995), many other extension models have been proposed to estimate the value of a stock. Examples include Feltham and Ohlson (1999), Pastor and Veronesi (2003), Bakshi and Chen (2005), Dong and Hirshleifer (2005), Yee (2008, 2010), and Hurley (2013), in addition to Bergeron (2013-A, 2013-B).

Nevertheless, none of these above-mentioned works develop a theoretical stock valuation model that explicitly integrates the long-run covariance between earnings growth and aggregate consumption growth, directly into the intrinsic value. In this sense, we can argue that the motivation of the present paper comes from the following observations: (1) the success of the recent concept of long-run risk; (2) the empirical success of the long-run covariance between earnings and consumption, as 
an appropriate measure of risk; (3) the importance of stock valuation in finance; (4) the absence of a theoretical stock valuation model that explicitly integrates the longrun earnings-consumption covariance as a measure of risk.

The development of our model involves the following steps. First, we characterise the hypothetical economy, using the intertemporal equilibrium framework of the consumption capital asset pricing model (CCAPM) of Rubinstein (1976), Lucas (1978) and Breeden (1979). Then, we show, under certain conditions, that earnings and stock prices are perfectly cointegrated and that random future prices and earnings are directly and stochastically related. Next, we demonstrate that a stock's earnings growth is positively related to its long-run covariance between earnings and aggregate consumption. Finally, we isolate the equilibrium stock price from the above relationship.

In this manner, we show that the intrinsic value of a stock is positively related to its long-run earnings growth rate, and negatively related to its earningsconsumption beta, measured by the long-run covariance between the earnings growth rate of the stock and the long-run growth rate of the aggregate consumption, divided by the long-run growth rate of the aggregate consumption.

Thereby, the main contribution of the model is to demonstrate that earningsconsumption betas affect firm theoretical values. In addition, our work suggests that the earnings-consumption beta represents an appropriate measure of risk (on the longrun). Moreover, it supports the use accounting variables for estimating risk. Besides, it reveals that expected earnings growth rates should be positively related to risk, in theory.

The remainder of this paper is organised as follows. Section 2 presents the intertemporal equilibrium framework. Section 3 derives the intrinsic value of a stock, using earnings and aggregate consumption. Section 4 concludes.

\section{The intertemporal equilibrium framework}

Following Bergeron (2013-B, p. 187, and others before), our model's intertemporal equilibrium framework considers a hypothetical economy, in which the representative investor maximises the time-separable utility function: ${ }^{4}$

$$
E_{t} \sum_{s=0}^{\infty} \delta^{s} U\left(\tilde{C}_{t+s}\right)
$$


subject to resource constraints, where $\tilde{C}_{t+s}$ is the aggregate consumption at time $t+s$ $(s=0,1,2, \ldots, \infty), U(\bullet)$ is an increasing concave and derivable function, and $\delta$ is the time discount factor $(0<\delta<1)$.

The solution to this problem, given by the first order necessary conditions, can be used to show that the price of stock $i$, at time $t, P_{i t}$, equals:

$$
P_{i t}=E_{t} \sum_{s=1}^{\infty} \delta^{s} \frac{U^{\prime}\left(\tilde{C}_{t+s}\right)}{U^{\prime}\left(C_{t}\right)} \tilde{D}_{i, t+s}
$$

where $\tilde{D}_{i, t+s}$ is the dividends of stock $i$ at time $t+s(s=1,2, \ldots, \infty)$, and where the premium represents a derivative of a function. ${ }^{5}$

The right-hand side of Equation (2) corresponds to the present value of all future cash flows (dividends), where the stochastic discount factor is equivalent to the intertemporal marginal rate of substitution between $t$ and $t+s \quad\left(\tilde{M}_{t+s}\right): \tilde{M}_{t+s} \equiv$ $\delta^{s} U^{\prime}\left(\tilde{C}_{t+s}\right) / U^{\prime}\left(C_{t}\right)$. With this notation, the equilibrium price of a stock becomes:

$$
P_{i t}=E_{t} \sum_{s=1}^{\infty} \tilde{M}_{t+s} \tilde{D}_{i, t+s}
$$

Recursively, Equation (3) can be expressed for a single period (between $t$ and $t+1$ ), in the following manner (see Cochrane, 2005, p. 27):

$$
P_{i t}=E_{t}\left[\tilde{M}_{t+1}\left(\tilde{P}_{i, t+1}+\tilde{D}_{i, t+1}\right)\right]
$$

where $\widetilde{P}_{i, t+1}$ represents the price of stock $i$ at time $t+1$, given the available information at time $t$. Moreover, since $P_{i t}$ is nonzero, and is known with the current information, it can thus be passed through the conditional expectation operator and divided on each side to indicate that:

$$
1=E_{t}\left[\tilde{M}_{t+1}\left(1+\tilde{r}_{i, t+1}\right)\right]
$$

where $\tilde{r}_{i, t+1}$ is the rate of return of stock $i$, between time $t$ and $t+1$ $\left(\widetilde{r}_{i, t+1} \equiv\left(\widetilde{P}_{i, t+1}+\widetilde{D}_{i, t+1}\right) / P_{i t}-1\right)$. In the same manner, if there is a short-term riskless asset, we can write: 


$$
1=E_{t}\left[\tilde{M}_{t+1}\left(1+r_{F, t+1}\right)\right]
$$

where $r_{F, t+1}$ is the rate of return of the riskless asset between time $t$ and $t+1$.

Equations (1) to (6) are well known. In the following section, we will combine these fundamental equilibrium conditions with earnings, to obtain a practical intrinsic value.

\section{$3 \quad$ Earnings and stock prices}

This section demonstrates that the equilibrium price of a stock is a function of its expected earnings growth rate, together with the covariance between its earnings and aggregate consumption. We begin by assuming that firms adjust their dividend payments toward a target dividend payout ratio. We then integrate earnings into the fundamental value of a long-lived asset to reveal that earnings and stock prices are cointegrated. Thereafter, we derive the intrinsic value of a stock using (first) the quadratic utility function, (second) the Taylor's expansion theorem, (third) the normal distribution, and (fourth) the linear process for earnings.

\subsection{Quadratic utility function}

The quadratic utility function is commonly used in finance (and economics). As Huang and Litzenberger (1988, p. 207) noted, explicit pricing formulae can be derived by assuming that the representative agent's utility function is quadratic. In addition, Huang and Litzenberger demonstrated that the risk-return relationship proposed by the canonical CCAPM can be easily derived using this simple utility function, which we also utilized in subsection 3.1 .

\section{Dividend payout ratio}

Similarly to Bakshi and Chen (2005) and Dong Hirshleifer (2005), our valuation stock model focuses on earnings and begins by assuming that dividends relate to earnings according to:

$$
\tilde{D}_{i, t+s}=d_{i} \tilde{X}_{i, t+s}+\widetilde{\varepsilon}_{i, t+s}
$$

with

$$
E_{t}\left[\tilde{\varepsilon}_{i, t+s}\right]=\operatorname{COV}_{t}\left[\tilde{\varepsilon}_{i, t+s}, \bullet\right]=0,
$$


where $d_{i}$ is the dividend payout ratio of stock $i ; \tilde{X}_{i, t+s}$ is the earnings of stock $i$, at time $t+s$; and $\tilde{\varepsilon}_{i, t+1}$ is the usual residual random term associated to Equation (7) for stock $i$ at time $t+s(s=1,2, \ldots, \infty)$.

The second line of Equation (7) simply supposes that the usual random term, given the available information in time $t$, displays a zero mean value and a zero covariance with any other random variables. As Dong and Hirshleifer (2005) mentioned, this parameterisation is inspired by the classic survey of Lintner (1956), which found that firms adjust toward a target dividend ratio. Thereby, integrating Equation (7) in Equation (3) indicates that:

$$
P_{i t}=E_{t} \sum_{s=1}^{\infty} \tilde{M}_{t+s}\left(d_{i} \tilde{X}_{i, t+s}+\tilde{\varepsilon}_{i, t+s}\right) .
$$

The standard assumptions regarding the residual terms $\widetilde{\varepsilon}_{i, t+s}$ also indicate that:

$$
P_{i t}=E_{t} \sum_{s=1}^{\infty} \tilde{M}_{t+s} d_{i} \tilde{X}_{i, t+s}
$$

As before, since the earnings value of stock $i$ at time $t, X_{i t}$, is known given the available information at time $t$, it thus be passed through the conditional expectation operator of Equation (9), to exhibit:

$$
P_{i t}=X_{i t} E_{t} \sum_{s=1}^{\infty} \tilde{M}_{t+s} d_{i} \tilde{X}_{i, t+s} / X_{i t}
$$

or, if we assemble the elements of the summation term:

$$
P_{i t}=X_{i t} E_{t}\left[\tilde{H}_{i t}\right]
$$

where variable $\tilde{H}_{i t}$ is defined in this manner: $\tilde{H}_{i t} \equiv \sum_{s=1}^{\infty} \tilde{M}_{t+s} d_{i} \tilde{X}_{i, t+s} / X_{i t}$. To simplify the notation, we can also express Equation (10b) in this compact form:

$$
P_{i t}=X_{i t} \phi_{i t}
$$

where $\phi_{i t} \equiv E_{t}\left[\tilde{H}_{i t}\right]$. Moreover, if the sequence of variables $\tilde{H}_{i t}(t=0,1,2, \ldots, \infty)$ is independent and identically distributed (i.i.d.), then we can write: 


$$
P_{i t}=X_{i t} \phi_{i}
$$

Therefore, given the available information at time $t$, Equation (11) suggests that the future price of the stock and the corresponding earnings are stochastically related in the following manner:

$$
\tilde{P}_{i, t+1}=\tilde{X}_{i, t+1} \phi_{i}
$$

Integrating Equations (7), (11) and (12) into the single period expression of the price of an asset, as formulated by Equation (4), allows us to write that:

$$
X_{i t} \phi_{i}=E_{t}\left[\tilde{M}_{t+1}\left(\tilde{X}_{i, t+1} \phi_{i}+d_{i} \tilde{X}_{i, t+1}+\tilde{\varepsilon}_{i, t+1}\right)\right],
$$

and the standard assumption regarding the residual term, allows us to express that:

$$
X_{i t} \phi_{i}=E_{t}\left[\tilde{M}_{t+1}\left(\tilde{X}_{i, t+1} \phi_{i}+d_{i} \tilde{X}_{i, t+1}\right)\right] .
$$

Dividing each side of Equation (14) by $X_{i t}$ and $\phi_{i}$, gives, after simple manipulations:

$$
1=E_{t}\left[\tilde{M}_{t+1}\left(\tilde{X}_{i, t+1} / X_{i t}+\phi_{i}^{-1} d_{i} \tilde{X}_{i, t+1} / X_{i t}\right)\right]
$$

Rearranging also indicates that:

$$
1=E_{t}\left[\tilde{M}_{t+1}\left(1+\tilde{g}_{i, t+1}^{E}\right)\left(1+\phi_{i}^{-1} d_{i}\right)\right]
$$

where $\tilde{g}_{i, t+1}^{E}$ is the earnings growth rate of stock $i$, between time $t$ and $t+1$ $\left(\tilde{g}_{i, t+1}^{E} \equiv \tilde{X}_{i, t+1} / X_{i t}-1\right)$.

Equation (16) presents a particular form of the Euler equation, expressed with earnings. Taking the expectation on each side permits us to release the index $t$ of the conditional operator, to reveals that:

$$
1=E\left[\tilde{M}_{t+1}\left(1+\tilde{g}_{i, t+1}^{E}\right)\left(1+\phi_{i}^{-1} d_{i}\right)\right] .
$$

In the same manner, taking the expectation on each of Equation (6), permits us to write: 


$$
1=E\left[\tilde{M}_{t+1}\left(1+r_{F, t+1}\right)\right] .
$$

Equation (17) minus Equation (18), gives, after simples manipulations, the following equality:

$$
0=E\left[\tilde{M}_{t+1}\left\{\left(1+\tilde{g}_{i, t+1}^{E}\right)\left(1+\phi_{i}^{-1} d_{i}\right)-\left(1+r_{F, t+1}\right)\right\}\right]
$$

The mathematical definition of covariance indicates that:

$$
\begin{aligned}
& \operatorname{COV}\left[\tilde{M}_{t+1},\left(1+\tilde{g}_{i, t+1}^{E}\right)\left(1+\phi_{i}^{-1} d_{i}\right)-\left(1+r_{F, t+1}\right)\right] \\
= & -E\left[\tilde{M}_{t+1}\right] E\left[\left(1+\tilde{g}_{i, t+1}^{E}\right)\left(1+\phi_{i}^{-1} d_{i}\right)-\left(1+r_{F, t+1}\right)\right] .
\end{aligned}
$$

From Equation (18), we have:

$$
E\left[\tilde{M}_{t+1}\right]=\left(1+r_{F, t+1}\right)^{-1},
$$

and the basic properties of mathematical covariance reveal, after simple manipulations, that:

$$
\operatorname{COV}\left[\tilde{M}_{t+1}, \tilde{g}_{i, t+1}^{E}\right]\left(1+\phi_{i}^{-1} d_{i}\right)=E\left[1+\tilde{g}_{i, t+1}^{E}\right]\left(1+\phi_{i}^{-1} d_{i}\right)\left(1+r_{F, t+1}\right)^{-1}+1 .
$$

Therefore, we can isolate the expected earnings growth rate of a stock, to show that equilibrium conditions predicate that:

$$
E\left[1+\tilde{g}_{i, t+1}^{E}\right]=\left(1+r_{F, t+1}\right) /\left(1+\phi_{i}^{-1} d_{i}\right)-\left(1+r_{F, t+1}\right) \operatorname{COV}\left[\tilde{M}_{t+1}, \tilde{g}_{i, t+1}^{E}\right]
$$

To get an explicit pricing formula, we will now make a standard assumption on the individual utility function.

\section{Utility function}

We assume that the utility function of the representative investor is quadratic, which implies, more specifically, that: $U\left(\tilde{C}_{t+1}\right)=\tilde{C}_{t+1}-(b / 2) \tilde{C}_{t+1}^{2}$, with $b>0$, and $\tilde{C}_{t+1}<$ $1 / b$. Integrating this specific utility function into Equation (23) shows that:

$$
E\left[1+\tilde{g}_{i, t+1}^{E}\right]=\frac{1+r_{F, t+1}}{1+\phi_{i}^{-1} d_{i}}-\left(1+r_{F, t+1}\right) \operatorname{COV}\left[\delta \frac{1-b \tilde{C}_{t+1}}{U^{\prime}\left(C_{t}\right)}, \tilde{g}_{i, t+1}^{E}\right]
$$

Using, again, the basic properties of covariance allows us to see that: 


$$
E\left[1+\tilde{g}_{i, t+1}^{E}\right]=\frac{1+r_{F, t+1}}{1+\phi_{i}^{-1} d_{i}}+\frac{\left(1+r_{F, t+1}\right) \delta b}{U^{\prime}\left(C_{t}\right)} \operatorname{COV}\left[\tilde{C}_{t+1}, \tilde{g}_{i, t+1}^{E}\right]
$$

Multiplying both sides of Equation (25) by $C_{t}$, and rearranging, indicates that:

$$
E\left[1+\tilde{g}_{i, t+1}^{E}\right]=\frac{1+r_{F, t+1}}{1+\phi_{i}^{-1} d_{i}}+\frac{\left(1+r_{F, t+1}\right) \delta b C_{t}}{U^{\prime}\left(C_{t}\right)} \operatorname{COV}\left[\tilde{C}_{t+1} / C_{t}, \tilde{g}_{i, t+1}^{E}\right],
$$

or, if we prefer (knowing that the covariance of a random variable with a constant is equal to zero):

$$
E\left[1+\tilde{g}_{i, t+1}^{E}\right]=\frac{1+r_{F, t+1}}{1+\phi_{i}^{-1} d_{i}}+\frac{\left(1+r_{F, t+1}\right) \delta b C_{t}}{U^{\prime}\left(C_{t}\right)} \operatorname{COV}\left[\tilde{g}_{t+1}^{C}, \tilde{g}_{i, t+1}^{E}\right]
$$

where $\tilde{g}_{t+1}^{C}$ is the growth rate of aggregate consumption, between time $t$ and $t+1$ $\left(\tilde{g}_{t+1}^{C} \equiv \tilde{C}_{t+1} / C_{t}-1\right)$. Multiplying on each side by the variance of the aggregate consumption growth rate, $\sigma^{2}\left[\tilde{g}_{t+1}^{C}\right]$, gives:

$$
E\left[1+\tilde{g}_{i, t+1}^{E}\right]=\frac{1+r_{F, t+1}}{1+\phi_{i}^{-1} d_{i}}+\frac{\left(1+r_{F, t+1}\right) \delta b C_{t} \sigma^{2}\left[\tilde{g}_{t+1}^{C}\right]}{U^{\prime}\left(C_{t}\right)} \frac{\operatorname{COV}\left[\tilde{g}_{t+1}^{C}, \tilde{g}_{i, t+1}^{E}\right]}{\sigma^{2}\left[\tilde{g}_{t+1}^{C}\right]}
$$

Rearranging, allows us to see that:

$$
E\left[1+\tilde{g}_{i, t+1}^{E}\right]=\left(1+r_{F, t+1}\right) /\left(1+\phi_{i}^{-1} d_{i}\right)+\lambda_{t} \beta_{i t}^{C E}
$$

where

$$
\begin{aligned}
& \lambda_{t} \equiv \delta\left(1+r_{F, t+1}\right) \sigma^{2}\left[\tilde{g}_{t+1}^{C}\right] C_{t} b / U^{\prime}\left(C_{t}\right), \\
& \beta_{i t}^{C E} \equiv \operatorname{COV}\left[\tilde{g}_{t+1}^{C}, \tilde{g}_{i, t+1}^{E}\right] / \sigma^{2}\left[\tilde{g}_{t+1}^{C}\right] .
\end{aligned}
$$

Since all the following values $\delta, r_{F, t+1}, \sigma^{2}\left[\tilde{g}_{t+1}^{C}\right], C_{t}, b$, and $U^{\prime}\left(C_{t}\right)$ are positive, by construction, then the parameter $\lambda_{t}$ is also positive $\left(\lambda_{t} \geq 0\right)$. The parameter $\beta_{i t}^{C E}$ can be viewed as an accounting consumption beta. More precisely, $\beta_{i t}^{C E}$ represents the short-run earnings-consumption beta of stock $i$, at time $t$, measured by the covariance between the earnings growth rate of the stock and the aggregate consumption growth rate, divided by the variance of the aggregate consumption 
growth rate. It measures the sensitivity of a company's earnings to aggregate consumption (reflecting economic activity).

Equation (28) represents an equilibrium condition for one period. It could be extended over several periods, or, if we prefer, in the long run.

\section{Many periods}

In the long run, the relationship between the company's earnings growth rate and its sensitivity to aggregate consumption can be obtained by summing from time zero $(t=$ $0)$ to time $T-1(t=T-1)$, that is to say:

$$
\sum_{t=0}^{T-1} E\left[1+\tilde{g}_{i, t+1}^{E}\right]=\sum_{t=0}^{T-1}\left[\left(1+r_{F, t+1}\right) /\left(1+\phi_{i}^{-1} d_{i}\right)+\lambda_{t} \beta_{i t}^{C E}\right]
$$

or, if we prefer, by using the basic properties of the summation operator:

$$
\sum_{t=0}^{T-1} E\left[1+\tilde{g}_{i, t+1}^{E}\right]=\left(1+\phi_{i}^{-1} d_{i}\right)^{-1} \sum_{t=0}^{T-1}\left(1+r_{F, t+1}\right)+\sum_{t=0}^{T-1} \lambda_{t} \beta_{i t}^{C E} .
$$

Multiplying by the scalar value $\sum_{t=0}^{T-1} \lambda_{t}$ on each side of Equation (30), yields:

$$
\sum_{t=0}^{T-1} E\left[1+\tilde{g}_{i, t+1}^{E}\right]=\left(1+\phi_{i}^{-1} d_{i}\right)^{-1} \sum_{t=0}^{T-1}\left(1+r_{F, t+1}\right)+\sum_{t=0}^{T-1} \lambda_{t} \sum_{t=0}^{T-1} w_{t} \beta_{i t}^{C E}
$$

where $w_{t} \equiv \lambda_{t} / \sum_{t=0}^{T-1} \lambda_{t}$, with $0<w_{t}<1$. Dividing by $T$ on each side of Equation (31) shows that:

$$
1+g_{i}^{E}=\left(1+r_{F}\right) /\left(1+\phi_{i}^{-1} d_{i}\right)+\lambda \beta_{i}^{C E}
$$

where $g_{i}^{E} \equiv \sum_{t=0}^{T-1} E\left[\tilde{g}_{i, t+1}^{E}\right] / T, r_{F} \equiv \sum_{t=0}^{T-1} r_{F, t+1} / T, \lambda \equiv \sum_{t=0}^{T-1} \lambda_{t} / T, \beta_{i}^{C E} \equiv \sum_{t=0}^{T-1} w_{t} \beta_{i t}^{C E}$

Here, the estimators $g_{i}^{E}, r_{F}$ and $\lambda$ represent, respectively, the arithmetic average of time values $E\left[\tilde{g}_{i, t+1}^{E}\right], r_{F, t+1}$ and $\lambda_{t}$, while $\beta_{i}^{C E}$ can be viewed as the weighted average sensitive coefficients of time values $\beta_{i t}^{C E}(t=1,2,3, \ldots, T-1)$. 
To put it differently, $g_{i}^{E}$ represents the long-run expected earnings growth rate of stock $i$; while $\beta_{i}^{C E}$ represents the long-run earnings-consumption beta of stock $i$, or, more simply, the earnings-consumption beta of stock $i$. Rearranging Equation (32), we can write:

$$
\left(1+g_{i}^{E}-\lambda \beta_{i}^{C E}\right) /\left(1+r_{F}\right)=1 /\left(1+\phi_{i}^{-1} d_{i}\right)
$$

or if we prefer:

$$
1 /\left[\left(1+g_{i}^{E}-\lambda \beta_{i}^{C E}\right) /\left(1+r_{F}\right)\right]-1=\phi_{i}^{-1} d_{i}
$$

At time $t=0$, Equation (11) indicates that: $\phi_{i}=P_{i 0} / X_{i 0}$; where the right hand side of the equality corresponds to the current price-earnings ratio of stock $i$. Therefore, we can write:

$$
1 /\left[\left(1+g_{i}^{E}-\lambda \beta_{i}^{C E}\right) /\left(1+r_{F}\right)\right]-1=d_{i} X_{i 0} / P_{i 0}
$$

or, after manipulations:

$$
\frac{1+r_{F}}{1+g_{i}^{E}-\lambda \beta_{i}^{C E}}-\frac{1+g_{i}^{E}-\lambda \beta_{i}^{C E}}{1+g_{i}^{E}-\lambda \beta_{i}^{C E}}=\frac{d_{i} X_{i 0}}{P_{i 0}}
$$

In this manner, we can easily isolate the equilibrium price of a stock to obtain a simple formula, expressed with accounting earnings. This may be written as:

$$
P_{i 0}=\frac{1+g_{i}^{E}-\lambda \beta_{i}^{C E}}{r_{F}+\lambda \beta_{i}^{C E}-g_{i}^{E}} d_{i} X_{i 0} .
$$

Equation (37) represents our main result. It shows that the equilibrium price of a stock depends on its current distributed earnings, expected earnings growth, and earnings-consumption beta. More precisely, Equation (37) reveals that the current equilibrium price of the stock is positively related to its current distributed earnings and its future earnings growth rate, and negatively related to its earnings-consumption beta, obtained from the long-run covariance between earnings and aggregate consumption.

Because the relationship between the price of the stock and its earningsconsumption beta is negative, the last parameter is viewed as a rightful measure of risk. ${ }^{6}$ In this sense, the above stock price expression supports the use of fundamental variables (as earnings) for estimating risk. 
From Equation (37), determining the intrinsic value of a stock requires the following steps: (1) establishing the economic exogenous variables (such as the rate of return of the riskless asset and the aggregate consumption growth rate), (2) observing the stock's current earnings distribution, and (3) estimating the stock's expected earnings growth rate and the stock's earnings-consumption beta. If the stock exhibits no covariance with aggregate consumption or no risk, then the determination of its intrinsic value is analogous to the classic constant growth model, with earnings. ${ }^{7}$

Besides, if we accept that the earnings-consumption beta represents a measure of risk, then Equation (32) suggests that a company's expected earnings growth rate is positively related to risk (in the long run). This point of view is intuitively appealing. It is also consistent with classic studies on the association between accounting variables and risk, in its standard form. ${ }^{8}$ Indeed, if we accept that growth in earnings arises from the return on new investment, and if we accept that return is positively related to risk, then we must accept that the earnings growth rate is positively related to risk. ${ }^{9}$ Our contribution, with Equation (32), is to characterise this theoretical relationship with a long-run accounting risk measure.

\section{The estimation of $\lambda$}

We can use the observable values of the market portfolio to facilitate the estimation of parameter $\lambda$. Indeed, from Equation (35) we can write:

$$
1 /\left[\left(1+g_{m}^{E}-\lambda \beta_{m}^{C E}\right) /\left(1+r_{F}\right)\right]-1=d_{m} X_{m 0} / P_{m 0},
$$

where the index $m$ indicates the market. Thus, after simple manipulations, we have:

$$
\lambda=\left[1+g_{m}^{E}-\left(1+r_{F}\right) /\left(1+d_{m} Y_{m}\right)\right] / \beta_{m}^{C E},
$$

where $Y_{m} \equiv X_{m 0} / P_{m 0}$. The last value simply refers to the earnings-price ratio of the entire market, which corresponds to the inverse of the popular price-earnings ratio. ${ }^{10}$ So, if we estimate (for example) that: (1) the earnings-consumption beta of the market is equal to $1,(2)$ the riskless asset equals $6 \%$, (3) the earnings growth rate of the market equals $5 \%$, (4) the market distribution ratio equals $50 \%$, and (5) the market price-earnings ratio equals 15 , then we can propose that parameter $\lambda$ should be equal to $2.42 \%$, as shown below;

$$
\begin{gathered}
\lambda=[1+0.05-(1+0.06) /(1+0.5 / 15)] / 1, \\
\lambda=1.05-(1.06) /(1.0333)=2.42 \% .
\end{gathered}
$$


A value of 1, for the earnings-consumption beta of the market, can be justified (for practical applications) knowing that the canonical CCAPM establishes an equivalency between market-dividend and aggregate-consumption.

In this section we used the quadratic utility function, for the sake of simplicity. However, this restrictive assumption can be ignored, using the Taylor series expansion, as we will demonstrate in the next section.

\subsection{Taylor series}

According to Taylor's theorem, we can evaluate the function $y=f(x)$ around the point $a$ in terms of its derivatives as follows:

$$
f(x)=f(a)+f^{\prime}(a)(x-a)+\frac{f^{\prime \prime}(a)(x-a)^{2}}{2 !}+\ldots+\frac{f^{(N)}(a)(x-a)^{N}}{N !} .
$$

When $N$ is equal to 1 , the Taylor series approximation indicates that:

$$
f(x) \approx f(a)+f^{\prime}(a)(x-a) .
$$

Therefore, as Breeden et al. (1989, p. 233) observed, an approximation of the marginal rate of substitution (MRS) can be obtained from the first-order Taylor series. Indeed, around $C_{t}$, we have:

$$
U^{\prime}\left(\tilde{C}_{t+1}\right) \approx U^{\prime}\left(C_{t}\right)+U^{\prime \prime}\left(C_{t}\right)\left(\tilde{C}_{t+1}-C_{t}\right)
$$

Integrating Equation (40) into Equation (23) suggests that the expected earnings growth of a stock approaches the following value:

$$
\begin{gathered}
E\left[1+\tilde{g}_{i, t+1}^{E}\right] \approx \frac{1+r_{F, t+1}}{1+\phi_{i}^{-1} d_{i}} \\
-\left(1+r_{F, t+1}\right) \operatorname{COV}\left[\delta \frac{U^{\prime}\left(C_{t}\right)+U^{\prime \prime}\left(C_{t}\right)\left(\tilde{C}_{t+1}-C_{t}\right)}{U^{\prime}\left(C_{t}\right)}, \tilde{g}_{i, t+1}^{E}\right] .
\end{gathered}
$$

Using the basic properties of mathematical covariance, and then rearranging, indicates that:

$$
E\left[1+\tilde{g}_{i, t+1}^{E}\right] \approx \frac{1+r_{F, t+1}}{1+\phi_{i}^{-1} d_{i}}-\frac{\delta U^{\prime \prime}\left(C_{t}\right)\left(1+r_{F, t+1}\right)}{U^{\prime}\left(C_{t}\right)} \operatorname{COV}\left[\tilde{C}_{t+1}-C_{t}, \tilde{g}_{i, t+1}^{E}\right]
$$

Multiplying by $C_{t}$ on each side of Equation (42) shows that: 


$$
E\left[1+\tilde{g}_{i, t+1}^{E}\right] \approx \frac{1+r_{F, t+1}}{1+\phi_{i}^{-1} d_{i}}-\frac{\delta U^{\prime \prime}\left(C_{t}\right)\left(1+r_{F, t+1}\right) C_{t}}{U^{\prime}\left(C_{t}\right)} \operatorname{COV}\left[\frac{\tilde{C}_{t+1}-C_{t}}{C_{t}}, \tilde{g}_{i, t+1}^{E}\right]
$$

Multiplying by $\sigma^{2}\left[\tilde{g}_{t+1}^{C}\right]$ on each side of Equation (43) reveals that:

$$
\begin{gathered}
E\left[1+\tilde{g}_{i, t+1}^{E}\right] \approx \frac{1+r_{F, t+1}}{1+\phi_{i}^{-1} d_{i}} \\
-\frac{\delta U^{\prime \prime}\left(C_{t}\right)\left(1+r_{F, t+1}\right) C_{t} \sigma^{2}\left[\tilde{g}_{t+1}^{C}\right]}{U^{\prime}\left(C_{t}\right)} \frac{\operatorname{COV}\left[\tilde{g}_{t+1,}^{C} \tilde{g}_{i, t+1}^{E}\right]}{\sigma^{2}\left[\tilde{g}_{t+1}^{C}\right]}
\end{gathered}
$$

Rearranging, allows us to see that:

$$
E\left[1+\tilde{g}_{i, t+1}^{E}\right] \approx\left(1+r_{F, t+1}\right) /\left(1+\phi_{i}^{-1} d_{i}\right)+\hat{\lambda}_{t} \beta_{i t}^{C E}
$$

where

$$
\begin{aligned}
& \hat{\lambda}_{t} \equiv \delta \sigma^{2}\left[\tilde{g}_{t+1}^{C}\right]\left(1+r_{F, t+1}\right)(-1) C_{t} U^{\prime \prime}\left(C_{t}\right) / U^{\prime}\left(C_{t}\right), \\
& \hat{\lambda}_{t} \equiv \delta \sigma^{2}\left[\tilde{g}_{t+1}^{C}\right]\left(1+r_{F, t+1}\right) R R A,
\end{aligned}
$$

with

$$
R R A \equiv-C_{t} U^{\prime \prime}\left(C_{t}\right) / U^{\prime}\left(C_{t}\right)
$$

Here, the term $R R A$ represents the relative risk aversion evaluated at $C_{t}$. Its value is necessarily positive, because the second derivative of the utility function must be negative, by construction, and the other values in the parameter must be positive. As a result, $\hat{\lambda}_{t}$ is also positive $\left(\hat{\lambda}_{t} \geq 0\right)$, if we admit that the variance of a random variable and the risk-free rate of return are greater than zero, just as the parameter $\delta$.

Given this, if we replicate the derivation from Equation (28) to Equation (32), we get (ignoring the approximation):

$$
1+g_{i}^{E}=\left(1+r_{F}\right) /\left(1+\phi_{i}^{-1} d_{i}\right)+\hat{\lambda} \hat{\beta}_{i}^{C E}
$$

where $\hat{\lambda} \equiv \sum_{t=0}^{T-1} \hat{\lambda}_{t} / T, \hat{\beta}_{i}^{C E} \equiv \sum_{t=0}^{T-1} \hat{w}_{t} \beta_{i t}^{C E}, \hat{w}_{t} \equiv \hat{\lambda}_{t} / \sum_{t=0}^{T-1} \hat{\lambda}_{t}$ 
Thus, using Equations (33) to (37), we can reproduce our main result concerning the equilibrium price of a stock. That is:

$$
P_{i 0}=\frac{1+g_{i}^{E}-\hat{\lambda} \hat{\beta}_{i}^{C E}}{r_{F}+\hat{\lambda} \hat{\beta}_{i}^{C E}-g_{i}^{E}} d_{i} X_{i 0},
$$

where $\hat{\lambda}$ and $\hat{\beta}_{i}^{C E}$ are similar to $\lambda$ and $\beta_{i}^{C E}$ derived previously, except that they do not refer to the quadratic assumption.

In the next section, we will increase the model's robustness using the usual normal distribution, without any specific utility function.

\subsection{Normal distribution}

According to Stein's lemma: if variable $\tilde{x}$ and variable $\tilde{y}$ are bivariate normal, the function $f(\tilde{x})$ is differentiable, and the expectation of $f^{\prime}(\tilde{x})$ is $<\infty$, then (see Cochrane 2005, p. 164):

$$
\operatorname{COV}[\tilde{y}, f(\tilde{x})]=E\left[f^{\prime}(\tilde{x})\right] \operatorname{COV}[\tilde{y}, \tilde{x}]
$$

So, if we suppose that $\tilde{C}_{t+1}$ and $\tilde{X}_{i, t+1}$ are bivariate normally distributed, then, from Equation (23), we can write that:

$$
E\left[1+\tilde{g}_{i, t+1}^{E}\right]=\frac{1+r_{F, t+1}}{1+\phi_{i}^{-1} d_{i}}-\delta\left(1+r_{F, t+1}\right) C O V\left[\frac{U^{\prime}\left(\tilde{C}_{t+1}\right)}{U^{\prime}\left(C_{t}\right)}, \tilde{g}_{i, t+1}^{E}\right]
$$

is equivalent to the following equality:

$$
E\left[1+\tilde{g}_{i, t+1}^{E}\right]=\frac{1+r_{F, t+1}}{1+\phi_{i}^{-1} d_{i}}-\frac{\delta\left(1+r_{F, t+1}\right) E\left[U^{\prime \prime}\left(\tilde{C}_{t+1}\right)\right]}{U^{\prime}\left(\tilde{C}_{t}\right)} \operatorname{COV}\left[\tilde{C}_{t+1}, \tilde{g}_{i, t+1}^{E}\right]
$$

Again, using the basic properties of mathematical covariance, and then rearranging, we get:

$$
E\left[1+\tilde{g}_{i, t+1}^{E}\right]=\frac{1+r_{F, t+1}}{1+\phi_{i}^{-1} d_{i}}-\frac{\delta\left(1+r_{F, t+1}\right) E\left[U^{\prime \prime}\left(\tilde{C}_{t+1}\right)\right] C_{t}}{U^{\prime}\left(\tilde{C}_{t}\right)} \operatorname{COV}\left[\frac{\tilde{C}_{t+1}}{C_{t}}, \tilde{g}_{i, t+1}^{E}\right]
$$

Also, multiplying by $\sigma^{2}\left[\tilde{g}_{t+1}^{C}\right]$ on each side of Equation (50) indicates that: 


$$
\begin{gathered}
E\left[1+\tilde{g}_{i, t+1}^{E}\right]=\frac{1+r_{F, t+1}}{1+\phi_{i}^{-1} d_{i}} \\
-\frac{\delta\left(1+r_{F, t+1}\right) E\left[U^{\prime \prime}\left(\tilde{C}_{t+1}\right)\right] C_{t} \sigma^{2}\left[\tilde{g}_{t+1}^{C}\right]}{U^{\prime}\left(\tilde{C}_{t}\right)} \frac{\operatorname{COV}\left[\tilde{g}_{t+1,}^{C} \tilde{g}_{i, t+1}^{E}\right]}{\sigma^{2}\left[\tilde{g}_{t+1}^{C}\right]} .
\end{gathered}
$$

Rearranging, one more time, allows us to see that:

$$
E\left[1+\tilde{g}_{i, t+1}^{E}\right]=\left(1+r_{F, t+1}\right) /\left(1+\phi_{i}^{-1} d_{i}\right)+\bar{\lambda}_{t} \beta_{i t}^{C E}
$$

where, $\bar{\lambda}_{t} \equiv \delta \sigma^{2}\left[\tilde{g}_{t+1}^{C}\right]\left(1+r_{F, t+1}\right)(-1) C_{t} E\left[U^{\prime \prime}\left(\tilde{C}_{t+1}\right)\right] / U^{\prime}\left(C_{t}\right)$.

As before, we can easily prove that the parameter $\bar{\lambda}_{t}$ is positive $\left(\bar{\lambda}_{t} \geq 0\right)$. Again, using Equations (28) to (32), we can write:

$$
1+g_{i}^{E}=\left(1+r_{F}\right) /\left(1+\phi_{i}^{-1} d_{i}\right)+\bar{\lambda} \bar{\beta}_{i}^{C E}
$$

where, $\bar{\lambda} \equiv \sum_{t=0}^{T-1} \bar{\lambda}_{t} / T, \bar{\beta}_{i}^{C E} \equiv \sum_{t=0}^{T-1} \bar{w}_{t} \beta_{i t}^{C E}, \bar{w}_{t} \equiv \bar{\lambda}_{t} / \sum_{t=0}^{T-1} \bar{\lambda}_{t}$.

Therefore, using Equations (33) to (37), we can express:

$$
P_{i 0}=\frac{1+g_{i}^{E}-\bar{\lambda} \bar{\beta}_{i}^{C E}}{r_{F}+\bar{\lambda} \bar{\beta}_{i}^{C E}-g_{i}^{E}} d_{i} X_{i 0} .
$$

where $\bar{\lambda}$ and $\bar{\beta}_{i}^{C E}$ are also similar to $\hat{\lambda}$ and $\hat{\beta}_{i}^{C E}$ derived previously, except that they do not refer to an approximation.

In the following section, we will conciliate the model's robustness using a linear assumption. Breeden et al. (1989, p. 233), Bansal et al. (2005, p. 1644), and Bergeron (2013-B, p. 186) inspired this procedure (with earnings).

\subsection{Linear function}

We assume that the relationship between earnings and consumption growth rates is generated by the following linear function:

$$
\tilde{g}_{i, t+1}^{E}=\alpha_{i t}^{E}+\beta_{i t}^{C E} \tilde{g}_{t+1}^{C}+\widetilde{\varepsilon}_{i, t+1}^{E}
$$


with

$$
E\left[\tilde{\varepsilon}_{i, t+1}^{E}\right]=\operatorname{COV}\left[\tilde{\varepsilon}_{i, t+1}^{E}, \bullet\right]=0,
$$

where $\alpha_{i t}^{E}$ is the intercept for stock $i$ at time $t ; \beta_{i t}^{C E}$ is (again) the earnings sensitivity to consumption for stock $i$ at time $t$; and $\tilde{\varepsilon}_{i, t+1}^{E}$ is the usual random term for stock $i$ at time $t+1 .^{11}$

Besides, we can easily prove that the coefficient of the earnings sensitivity to consumption (the beta expressed into the last equation), is equivalent to the parameter presented previously: ${ }^{12}$

$$
\beta_{i t}^{C E}=\operatorname{COV}\left[\tilde{g}_{t+1}^{C}, \tilde{g}_{i, t+1}^{E}\right] / \sigma^{2}\left[\tilde{g}_{t+1}^{C}\right]
$$

Integrating Equation (55) into Equation (23) indicates that the expected earnings growth of a stock equals:

$$
E\left[1+\tilde{g}_{i, t+1}^{E}\right]=\frac{1+r_{F, t+1}}{1+\phi_{i}^{-1} d_{i}}-\left(1+r_{F, t+1}\right) \operatorname{COV}\left[\tilde{M}_{t+1}, \alpha_{i t}^{E}+\beta_{i t}^{C E} \tilde{g}_{t+1}^{C}+\tilde{\varepsilon}_{i, t+1}^{E}\right]
$$

Using the basic properties of covariance, one more time, allows us to write:

$$
E\left[1+\tilde{g}_{i, t+1}^{E}\right]=\frac{1+r_{F, t+1}}{1+\phi_{i}^{-1} d_{i}}-\left(1+r_{F, t+1}\right) \operatorname{COV}\left[\tilde{M}_{t+1}, \tilde{g}_{t+1}^{C}\right] \beta_{i t}^{C E},
$$

Rearranging also allows us to write:

$$
E\left[1+\tilde{g}_{i, t+1}^{E}\right]=\left(1+r_{F, t+1}\right) /\left(1+\phi_{i}^{-1} d_{i}\right)+\hat{\lambda}_{t} \beta_{i t}^{C E},
$$

where $\hat{\lambda}_{t} \equiv-\left(1+r_{F, t+1}\right) \operatorname{COV}\left[\tilde{M}_{t+1}, \tilde{g}_{t+1}^{C}\right]$, and the parameter $\hat{\lambda}_{t}$ is positive $\left(\hat{\lambda}_{t} \geq 0\right)$ because the covariance between $\tilde{M}_{t+1}$ and $\tilde{g}_{t+1}^{C}$ is, by construction, negative. Using Equations (28) to (32), we get:

$$
1+g_{i}^{E}=\left(1+r_{F}\right) /\left(1+\phi_{i}^{-1} d_{i}\right)+\hat{\lambda} \widehat{\beta}_{i}^{C E}
$$

where $\hat{\lambda} \equiv \sum_{t=0}^{T-1} \widehat{\lambda}_{t} / T, \quad \widehat{\beta}_{i}^{C E} \equiv \sum_{t=0}^{T-1} \widehat{w}_{t} \beta_{i t}^{C E}, \quad \widehat{w}_{t} \equiv \hat{\lambda}_{t} / \sum_{t=0}^{T-1} \widehat{\lambda}_{t}$. 
Finally, using Equations (33) to (37), we have:

$$
P_{i 0}=\frac{1+g_{i}^{E}-\hat{\lambda} \widehat{\beta}_{i}^{C E}}{r_{F}+\hat{\lambda} \widehat{\beta}_{i}^{C E}-g_{i}^{E}} d_{i} X_{i 0},
$$

where $\hat{\lambda}$ and $\widehat{\beta}_{i}^{C E}$ are also similar to $\bar{\lambda}$ and $\bar{\beta}_{i}^{C E}$ derived previously, except that they come from the earnings linear process expressed by Equation (55).

\section{Conclusion}

Following the traditional discounted cash flow approach, many extension models have been proposed to estimate the value of a stock. The primary contribution of this paper is to develop a new stock valuation model that takes into account the long-run covariance between earnings and aggregate consumption. Put it differently, the primary contribution of this theoretical paper is to develop a new stock valuation model that integrates the recent concept of long-run risk, using accounting variables. ${ }^{13}$

Starting from the intertemporal framework of the CCAPM, we showed that the equilibrium price of a stock is positively related to its long-run earnings growth rate, and negatively related to its earnings-consumption beta, obtained from its long-run covariance between earnings growth and aggregate consumption growth. In so doing, this paper extends the recent and promising concept of long-run risk to accounting earnings. ${ }^{14}$ In addition, it supports the use of accounting variables for estimating risk. Moreover, it demonstrates that the relationship between expected earnings growth and risk is positive. Overall, it offers a new tool for stock valuation (especially for ordinary stocks).

Finally, the intertemporal equilibrium framework of our model considered a hypothetical economy, in which the representative investor maximises a timeseparable utility function. For future research, it may be suitable to see how we could generalize the utility function.

\section{Notes}

1 In general, an accounting beta represents the covariance between the earnings of a company and the market earnings, divided by the variance of the market earnings. Random earnings $\left(\mathrm{E}_{1}\right)$ can be deflated by current prices $\left(\mathrm{P}_{0}\right)$, book values $\left(\mathrm{B}_{0}\right)$, or earnings $\left(\mathrm{E}_{0}\right)$, using the following ratios: $\mathrm{E}_{1} / \mathrm{P}_{0}, \mathrm{E}_{1} / \mathrm{B}_{0}$, and $\mathrm{E}_{1} / \mathrm{E}_{0}$. 
2. In their study, Ismail and Kim (1989) use four accounting variables: (1) income available to common equity; (2) income available to common equity plus depreciation; (3) income available to common equity plus depreciation and deferred taxes; and (4) cash flows generated from continuing operations.

3 See Chapter 18 in Elton et al. (2014).

4 In this document, the operators $E_{t}, V A R_{t}$, and $C O V_{t}$ refer respectively to mathematical expectation, variance, and covariance, where index $t$ implies that we consider the available information at time $t$. Furthermore, the tilde $(\sim)$ indicates a random variable.

5 See Rubinstein (1976) or Cochrane (2005), Chapter 1.

6 Equation (28) demonstrates that $\lambda_{t}$ is positive (for every $t$ ). As a result, parameter $\lambda$ in Equation (37) is also positive.

7 See the constant growth model, Chapter 18, in Elton et al. (2014).

8 On the positive relationship between growth and risk, see, for example, the classic study of Beaver $e t$ al. (1970), and others.

9 See, again, Chapter 18 in Elton et al. (2014).

10 The earnings-price ratio (earnings divided by price) is sometimes called the earnings-yield.

11 The second line of Equation (55) assumes (as before) that the random standard term ( $\varepsilon$ ) presents a zero mean value and a zero correlation value with any other variables.

12 If $x, y$ and e represent general variables, and if $y=a+b x+e$, where $\operatorname{COV}(x, e)=0$, then $\operatorname{COV}(x$, $y)=\operatorname{COV}(x, a+b x+e)=\operatorname{COV}(x, x) b$. Therefore: $b=\operatorname{COV}(x, y) / \sigma^{2}(x)$.

13 Ohlson (1995), Feltham and Ohlson (1999), and Bergeron (2013-A), for example, also present theoretical papers on stock valuation that offer direct practical implications.

14 According to Ferson et al. (2013), the long-run risk model following Bansal and Yaron (2004) has been a phenomenal success.

\section{References}

Baginski, P., and Wahlen, J.M. (2003) 'Residual income risk, intrinsic values, and share prices', The Accounting Review, Vol. 78 No. 1, pp. 327-351.

Bakshi, G., and Chen, Z. (2005) 'Stock valuation in dynamic economies', Journal of Financial Markets, Vol. 8 No. 2, pp. 111-151.

Ball, R., and Sadka, G. (2015) 'Aggregate earnings and why they matter', Journal of Accounting Literature, Vol. 34 No. 1, pp. 39-57.

Bansal, R., Dittmar, R.F. and Kiku, D. (2009) 'Cointegration and consumption risks in asset returns', Review of Financial Studies, Vol. 22 No. 3, pp. 1343-1375. 
Bansal, R., Dittmar, R.F. and Lundblad, C. (2005) 'Consumption, dividends, and the cross-section of equity returns’, The Journal of Finance, Vol. 60 No. 4, pp. 1639-1672.

Bansal, R. and Kiku, D. (2011) 'Cointegration and long-run asset allocation', Journal of Business and Economic Statistics, Vol. 29 No. 1, pp. 161-173.

Bansal, R. and Shaliastovich, I. (2013) 'A long-run risks explanation of predictability puzzles in bond and currency markets', The Review of Financial Studies, Vol. 26 No. 1, pp. 1-33.

Bansal, R. and Yaron, A. (2004) 'Risks for the long run: A potential resolution of asset pricing puzzles', The Journal of Finance, Vol. 59 No. 4, pp. 1481-1509.

Basu, S. (1977) 'Investment performance of common stock in relation to their price earnings ratios: a test of efficient market hypothesis', The Journal of Finance, Vol. 32 No. 3, pp. 663-682.

Beaver, W., Kettler, P. and Scholes, M. (1970) 'The association between market determined and accounting determined risk measures', The Accounting Review, Vol. 45 No. 4, pp. 654-682.

Beaver, W., and Manegold, J. (1975) 'The association between market-determined and accountingdetermined measures of systematic risk: some further evidence', Journal of Financial and Quantitative Analysis, Vol. 10 No. 2, pp. 231-284.

Beeler, J. and Campbell, J. (2012) 'The long-run risks model and aggregate asset prices: an empirical assessment', Critical Finance Review, Vol. 1 No. 1, pp. 141-182.

Bergeron, C. (2013-A) 'Dividend growth, stock valuation, and long-run risk', Journal of Economics and Finance, Vol. 37 No. 4, pp. 547-559.

Bergeron, C. (2013-B) 'Dividend sensitivity to economic factors, stock valuation, and long-run risk', Finance Research Letters, Vol. 11 No. 3, pp. 184-195.

Breeden, D.T. (1979) 'An intertemporal asset pricing model with stochastic consumption and investment opportunities', Journal of Financial Economics, Vol. 7 No. 3, pp. 265-296.

Breeden, D.T., Gibbons, M.R. and Litzenberger, R.H. (1989) 'Empirical tests of the consumptionoriented CAPM', The Journal of Finance, Vol. 44 No. 2, pp. 231-262.

Cochrane, J.H. (2005), Asset Pricing. Princeton University Press, Princeton N.J.

Da, Z. (2009), 'Cash flow, consumption risk, and the cross-section of stock returns', The Journal of Finance, Vol. 64 No. 2, pp. 923-956.

Da, Z. and Warachka, M.C. (2009), 'Casflow risk, systematic earnings revisions, and the cross-section of stock returns', Journal of Financial Economics, Vol. 94 No. 2, pp. 118-136.

Dong, M., and Hirshleifer, D. (2005) 'A generalized earnings-based stock valuation model', The Manchester School, Vol. 73 No. 9, pp. 1-31.

Elton, E., Gruber, M., Brown, S.J. and Goetzmann, W.N. (2014) Modern Portfolio Theory and Investment Analysis. Wiley, $9^{\text {th }}$ Edition, NewYork, N.Y. (752 p.).

Epstein, L. and Zin, S. (1989) 'Substitution, risk aversion and the temporal behavior of consumption and asset returns: A theoretical framework', Econometrica, Vol. 57 No. 4, pp. 937-969.

Feltham, G.A. and Ohlson, J.A. (1999) 'Residual earnings valuation with risk and stochastic interest rates', The Accounting Review, Vol. 74 No. 2, pp. 165-183.

Ferson, W., Nallareddy, S. and Xie, B. (2013) 'The "out-of-sample" performance of long-run risk models', Journal of Financial Economics, Vol. 107 No. 3, pp. 537-556.

Gordon, M. (1962) The Investment, Financing, and Valuation of the corporation. Irwin, Homewood Ill (256 p.). 
Goyal, A. (2012) 'Empirical cross-sectional asset pricing: a survey', Financial Markets and Portfolio Management, Vol. 26 No. 1, pp. 3-38.

Hansen, L.P., Heaton, J.C. and Li, N. (2008) 'Consumption strikes back?: Measuring long-run risk', Journal of Political Economy, Vol. 116 No. 2, pp. 260-302.

Huang, C. and Litzenberger, R.H. (1988) Foundations for financial economics. Elsevier Science Publishing, New York, N.Y.

Hurley, J.W. (2013) 'Calculating first moments and confidence intervals for generalized stochastic dividend discount models', Journal of Mathematical Finance, Vol. 3 No. 2, pp. 57-68.

Ismail, B.E., and Kim, M.K. (1989) 'On the association of cash flow variables with market risk: further evidence', The Accounting Review, Vol. 64 No. 1, pp. 125-136.

Karels, G.V., and Sackley, W.H. (1993) 'The relationship between market and accounting betas for commercial banks', Review of Financial Economics, Vol. 2 No. 2, pp. 59-72.

Lintner, J. (1956) 'Distribution of incomes of corporations among dividends, retained earnings, and taxes', American Economic Review, Vol. 76 No. 2, pp. 97-118.

Lucas, R.E. (1978) 'Asset prices in an exchange economy', Econometrica, Vol. 46 No.6, pp. 14291445.

Nekrasov, A., and Shroff, P.K. (2009) 'Fundamentals-based risk measurement in valuation', The Accounting Review, Vol. 84 No. 6, pp. 1983-2011.

Ohlson, J.A. (1995) 'Earnings, book values, and dividends in equity valuation', Contemporary Accounting Research, Vol. 11 No. 2, pp. 661-687.

Pastor, L., and Veronesi, P. (2003) 'Stock valuation and learning about profitability', The Journal of Finance, Vol. 58 No. 5, pp. 1749-1789.

Rubinstein, M. (1976), 'The valuation of uncertain income streams and the pricing of options', The Bell Journal of Economics, Vol. 7 No. 2, pp. 407-425.

Schlueter, T., and Sievers, S. (2014) 'Determinants of market beta: the impacts of firm-specific accounting figures and market conditions', Review of Quantitative Finance and Accounting, Vol. 42 No. 3, pp. 535-570.

Yee, K.K. (2008) 'A Bayesian framework for combining valuation estimates', Review of Quantitative Finance and Accounting, Vol. 30 No. 3 , pp. 339-354.

Yee, K.K. (2010) 'Combining fundamental measures for stock selection', In Handbook of Quantitative Finance and Risk Management, pp. 185-202, Springer, New York, N.Y. 